\title{
A study on topography of clavicular neurovascular foramina and its surgical implications
}

\author{
Venkatesh Kamath ${ }^{1}$, Saroj Kumar,"*, Muhammed Asif ${ }^{3}$, Shivarama Bhat ${ }^{4}$, Md. Tabrej Alam ${ }^{5}$ \\ ${ }^{1,2}$ Associate Professor, ${ }^{3}$ Lecturer, ${ }^{4}$ Professor, ${ }^{5}$ Assistant Professor, Dept. of Anatomy, ${ }^{1}$ G.S.L. Medical College, Rajahmundry, \\ Andhra Pradesh, ${ }^{2,5}$ Hind Institute of Medical Sciences, Sitapur, Uttar Pradesh, ${ }^{3,4}$ Yenepoya Medical College, Mangalore, \\ Karnataka, India
}

*Corresponding Author:

Email: saroj_kumar95@yahoo.com

Received: $15^{\text {th }}$ November, 2018

Accepted: $04^{\text {th }}$ January, 2018

\begin{abstract}
Aim: To study the topography of clavicular nutrient foramina.

Materials and Methods: The topography of nutrient foramina was studied in 71 clavicles. The mean foraminal index was calculated using Hughes formula. The direction of foramen was also observed.

Results: The mean foraminal index was 36.31. The foramen was observed in the middle third of the clavicle in $87.32 \%$ cases and medial third in $12.68 \%$ cases. The foramen was observed in the inferior surface in $49.3 \%$ cases and posterior surface in $50.7 \%$ cases. No foramina were observed in the superior surface and in the lateral third of the clavicle.

Conclusion: The foramina are mainly observed in the middle third of the clavicle. Standard literatures describe that foramen are mainly seen in the inferior surface but in our study, we observed foramina in both inferior and posterior surface in high frequency. This knowledge of distribution of foramina is of great importance for orthopaedic surgeons in surgeries like internal fixation and bone grafting.
\end{abstract}

Keywords: Clavicle, Foraminal index, Periosteal vessels, Nutrient foramen, Surgical implications.

\section{Introduction}

The clavicle is the only long bone that lies horizontally. The medial two third of its shaft is cylindrical with four surfaces and the lateral one third is flattened. The nutrient foramen is usually found on the inferior surface in the lateral part of subclavian groove as described in standard anatomical literatures. ${ }^{1}$ Long bones have a shaft called the diaphysis supplied by a nutrient artery which enters it through the nutrient foramen. ${ }^{2}$ The medial third is supplied by nutrient branches of internal thoracic, middle third by suprascapular and the lateral third by the branches arising from the thoraco-acromial artery. ${ }^{3,4}$ However, it is also opined that these branches are periosteal as the term nutrient artery refers to a branch that enters the medullary cavity of the bone and in the clavicle, such a cavity is absent. ${ }^{4}$ Clavicle ossifies first in the body by membranous ossification. A fascicle of supraclavicular nerve often passes through the nutrient foramen; hence it is called neuro-vascular foramen. ${ }^{5}$ A thorough knowledge of topography of nutrient foramina is essential for orthopaedic surgeons to preserve the blood supply of the clavicle during surgery. ${ }^{6}$ There are innumerable studies on nutrient foramina of long bones of upper and lower extremity. ${ }^{7-10}$ However, there is very little literature available on clavicular nutrient foramina. Moreover, there are several views regarding blood supply of clavicle some of them claiming that clavicle is supplied mainly by periosteal arteries rather than through a nutrient artery ${ }^{4}$ and these views will be discussed in this study.

\section{Materials and Methods}

The study was conducted in G.S.L. Medical College, Rajahmundry. This study involved 71 clavicles. The sex and age determination of the bones was not done. Only adult bones without any pathological deformities were selected. The foramen was identified by a magnifying lens. A 24-gauge needle was used to confirm its patency. The length of 71 clavicles was measured as shown in the figure 1 . The nutrient foramen was identified, its position was marked by a needle and its distance from the sternal end of the bone (SF) was measured as shown in figure 1 . The foraminal index was then calculated by Hughes formula. ${ }^{11}$ The topography of the foramina was studied using foraminal index and the position was classified as being present in the medial third, middle third or the lateral third of the clavicle. Less than 33.33 foraminal index indicates foramen location in medial third, 33.33 to 66.66 in middle third and above 66.66 in lateral third. The number of foramina and the surface on which it is present was also noted.

Foraminal Index $=$ Distance of the foramen from the sternal end of the bone $\times 100$

$$
\text { Total length of the bone }
$$




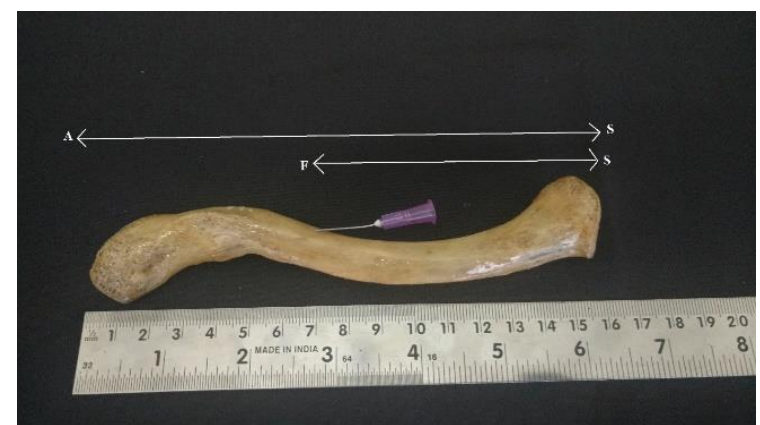

Fig. 1: Depicts the technique of measurement of total length and foraminal index. A depicts acromial end, $S$ depicts sternal end and $F$ depicts nutrient foramen. AS is the total length of bone and SF being the distance of the foramen from the sternal end

\section{Results}

The foramen was observed in the medial third of the clavicle in $12.68 \%$ cases and in the middle third of the clavicle in $87.32 \%$ cases. The mean foraminal index was 36.31 which suggests that the foramina are usually observed in the middle third of the clavicle. No foramina were observed in the lateral third of the clavicle. The foramina were observed in the inferior surface in $49.3 \%$ cases and in the posterior surface in $50.7 \%$ cases. No foramina were observed in the superior surface. The results show that the foramina are seen most commonly in the middle third of the clavicle in the posterior or inferior surface. Two clavicles where no foramina were observed, were presumably supplied by periosteal arteries. Double foramina were observed in 2 clavicles.

Table 1: Depicts the topography of nutrient foramina in the clavicle

\begin{tabular}{|l|c|c|c|}
\hline \multirow{2}{*}{$\begin{array}{c}\text { Distribution of } \\
\text { Foramina }\end{array}$} & \multicolumn{2}{c|}{ Side } & \multirow{2}{*}{ Total (71) } \\
\cline { 2 - 3 } & Right (33) & Left (38) & \\
\hline Medial third of clavicle & $5(15.15 \%)$ & $4(10.53 \%)$ & $9(12.68 \%)$ \\
\hline Middle third of clavicle & $28(84.85 \%)$ & $34(89.47 \%)$ & $62(87.32 \%)$ \\
\hline Lateral third of clavicle & 0 & 0 & 0 \\
\hline Mean foraminal index & 35.92 & 36.65 & 36.31 \\
\hline Superior surface & 0 & 0 & 0 \\
\hline Inferior surface & $13(18.31 \%)$ & $22(30.98 \%)$ & $35(49.3 \%)$ \\
\hline Posterior surface & $20(28.17)$ & $16(22.54 \%)$ & $36(50.7 \%)$ \\
\hline
\end{tabular}

\section{Discussion}

The most significant point that needs to be discussed is whether the clavicle is supplied by periosteal vessels or the nutrient artery. Some authors believe that though the clavicle receives a nutrient artery its role in supplying nutrition to the bone is insignificant as the clavicle is a bone without a medullary cavity. Moreover, a good periosteal vascular network is observed all around the bone with contributions from internal thoracic, suprascapular and the thoraco-acromial artery. ${ }^{3,4}$ In this study, 2 clavicles had no nutrient foramina and it is evident that these bones were supplied by the periosteal vascular network. Therefore, in surgeries involving the clavicle or the clavicular region the surgeon must take care to preserve both the nutrient artery and more importantly the periosteal vascular network. In our study we observed the presence of a nutrient artery consistently in 69 out of 71 clavicles and hence we feel that even the nutrient artery has a substantial role in supplying nutrition to the clavicle. A similar view is expressed by several other authors. ${ }^{3,5,6,12}$

It was observed that in most of the clavicles the nutrient foramina were directed away from the sternal end of the clavicle. This signifies that the sternal end is the growing end of the bone.
The nutrient artery plays an important role in nutrition especially during early ossification. ${ }^{13}$ However, the position of nutrient foramen is described as being present in the inferior surface in most standard anatomical literatures. ${ }^{14}$ In contrast to this observation we observed that $50.7 \%$ foramina in the posterior surface and $49.2 \%$ foramina in the inferior surface. A similar observation was made by Tanna and Tanna in 2014 who observed $50.8 \%$ foramina in the posterior surface and $49.3 \%$ foramina in the inferior surface..$^{15}$ Murlimanju BV et al. have also reported $69.2 \%$ foramina in the posterior surface. ${ }^{6}$ These studies show, that an equally high incidence of foramina is observed in the posterior surface and perhaps it is time for the standard text books to revise older statements stating foraminal predominance in the inferior surface.

The mean foraminal index in our study is 36.31 indicating that the foramina are usually present in the middle third of the clavicle. Murlimanju BV et al. reported a mean foraminal index of $44.72^{6}$ and Tanna and Tanna reported a mean foraminal index of $49.01 . .^{15}$ All the studies therefore indicate that the nutrient foramen is observed mainly in the middle third of the clavicle. 


\section{Surgical implications of foraminal topography in clavicle}

A sound knowledge of foraminal topography helps the surgeon to preserve the vasculature of the bone. In procedures such as internal fixation and bone grafting it is very essential to preserve vascularity to ensure success of the procedure. In bone grafts involving the clavicle the thoraco-acromial branch of axillary artery is often preserved. ${ }^{16}$ In penetrating injuries and fractures involving the bone the vasculature plays a major role in osteocyte regeneration and therefore is the most significant prognostic factor.

\section{Conclusion}

The clavicle is a bone supplied by both periosteal arteries and nutrient artery. Hence, it is essential to preserve both the nutrient and the periosteal arteries in procedures such as internal fixation and bone grafting involving the clavicle. The nutrient artery is most often located in the middle third and the same is described in other literatures. The standard texts describe that the nutrient foramen in the clavicle is found in the inferior surface. However, in the study we observe that the foramina are found both in the posterior surface and inferior surface with high frequency. This knowledge is vital for an orthopaedic surgeon while performing surgeries in the clavicle.

\section{References}

1. Standring S. Gray's Anatomy: The Anatomical Basis of Clinical Practice, 40th edn. London, UK: Elsevier, 2008. pp. 791-5.

2. Lewis OJ. The blood supply of developing long bones with special reference to the metaphysis. J Bone Joint Surg Br. 1956. 38-B: 928-33.

3. Havet E, Duparc F, Tobenas-Dujardin A-C et al. Vascular anatomical basis of clavicular non-union. Surg Radiol Anat. 2008. 30:23-8.

4. Knudsen FW, Andersen M, Krag C. The arterial supply of the clavicle. Surg Radiol Anat. 1989.11:211-4.

5. Kumar R, Lindell MM, Madewell JE et al. The clavicle: normal and abnormal. Radiographics. 1989. 9:677-706.

6. Murlimanju BV, Prabhu LV, Pai MM, Yadav A, Dhananjaya KVN, Prashanth KU. Neurovascular foramina of the human clavicle and their clinical significance. Surg Radiol Anat. 2011.33(8):679-82.

7. Forriol Campos F, Gomez L, Gianonatti M et al. A study of the nutrient foramina in human long bones. Surg Radiol Anat. 1987. 9:251-5.

8. Gumusburun E, Yucel F, Ozkan Y et al. A study of the nutrient foramina of lower limb long bones. Surg Radiol Anat. 1994. 16:409-12.

9. Kamath V, Bhat S, Asif M, Avadhani R. Topography of diaphyseal nutrient foramina of femora and their implications in bone grafting. NJCA. 2016. 5 (3):127-32.

10. Kamath V, Asif M, Bhat S, Avadhani R. Primary nutrient foramina of tibia and fibula and their surgical implications. IJCAP. 2016. 3 (1):41-4.

11. Hughes $\mathrm{H}$. The factors determining the direction of the canal for the nutrient artery in the long bones of mammals and birds. Acta Anat. 1952. 15:261-86.
12. Fischer LP, Carret JP. Vascularisation artérielle des os chez l'homme. Bull Assoc Anat. 1978. 62:419-54.

13. Kizilkanat E, Boyan N, Ozsahin ET et al. Location, number and clinical significance of nutrient foramina in human long bones. Ann Anat. 2007. 189:87-95.

14. Standring S. Gray's anatomy. The anatomical basis of clinical practice, 39th edn. Churchill Livingstone, Spain. 2006. pp 817-8.

15. Tanna NA, Tanna VA. Anatomical variation in position, direction, and number of nutrient foramina in clavicles. Int J Med Sci Public Health. 2015. 4:357-9.

16. Reid CD, Taylor GI, Waterhouse N. The clavicular head of pectoralis major musculocutaneous free flap. Br J Plast Surg. 1986. 39:57-65. 